TITLE:

\title{
Analysis of Car-following Behavior on Sag and Curve Sections at Intercity Expressways with Driving Simulator
}

\section{AUTHOR(S):}

Yoshizawa, Ryuji; Shiomi, Yasuhiro; Uno, Nobuhiro; lida, Katsuhiro; Yamaguchi, Masao

\section{CITATION:}

Yoshizawa, Ryuji ... [et al]. Analysis of Car-following Behavior on Sag and Curve Sections at Intercity Expressways with Driving Simulator. International Journal of Intelligent

Transportation Systems Research 2012, 10(2): 56-65

\section{ISSUE DATE:}

2012-05

URL:

http://hdl.handle.net/2433/155092

\section{RIGHT:}

The final publication is available at www.springerlink.com; This is not the published version. Please cite only the published version.; この論文 は出版社版でありません。引用の際には出版社版をご確認ご利用くだ さい。 


\title{
Analysis of Car-following Behavior on Sag and Curve Sections at Intercity Expressways with Driving Simulator
}

\author{
Ryuji Yoshizawa $^{* 1}$ Yasuhiro Shiomi $^{* 1}$ Nobuhiro Uno ${ }^{* 2}$ Katsuhiro Iida ${ }^{* 3}$ Masao Yamaguchi ${ }^{* 3}$ \\ Graduate School of Engineering, Kyoto University ${ }^{* 1}$ \\ (C-1-2, Kyoto University Katsura, Nishikyo-ku, Kyoto, 615-8540, Japan, +81-75-383-3235, \\ shiomi@trans.kuciv.kyoto-u.ac.jp) \\ Graduate School of Management, Kyoto University ${ }^{* 3}$ \\ (C-1-2, Kyoto University Katsura, Nishikyo-ku, Kyoto, 615-8540, Japan, +81-75-383-3234, \\ uno@trans.kuciv.kyoto-u.ac.jp) \\ Graduate School of Engineering, Osaka University ${ }^{* 3}$ \\ (2-1, Yamadagaoka, Suita city, Osaka, 565-0871, Japan, +81-6-6879-7611, \\ iida@civil.eng.osaka-u.ac.jp)
}

We analyzed the influence of road alignments such as sags and curves and the leading vehicle's behavior on carfollowing behavior in a driving simulator experiment. Parameters of a car-following model were estimated from following-vehicle trajectory data collected for 37 participants. Then, relationships between the parameters and environmental factors were analyzed. The results showed that the parameters of the following-behavior model were significantly influenced by expressway alignments such as sags and curves, whereas differences in the leading vehicle's behavior did not significantly affect the estimated parameters. These findings indicate that measures to assist the following vehicle's acceleration and deceleration such as adaptive cruise control could be effective in preventing the breakdown of traffic flow.

Key words: car-following behavior, driving simulator, road alignment, in-laboratory experiment

\section{Introduction}

Some sections of Japanese freeways, including sags and tunnel entrances without any lane drops, merging, or diverging, become bottlenecks and congestion queues often appear behind these sections ${ }^{[1]}$. Sag bottlenecks are major causes of traffic congestion on Japanese freeways. Furthermore, the risk of traffic accidents is much higher in congested traffic state than in free flow state ${ }^{[2]}$. Too enhance both efficiency and safety, measures to prevent traffic breakdown and to mitigate traffic congestion at sag bottlenecks are needed. To do so, precise understanding of such bottleneck phenomena is required.

Many attempts to understand the mechanisms of traffic breakdown and queue formation on basic sections of freeways, including sags and tunnels, have been made since Koshi et al. ${ }^{[3]}$ noted that bottlenecks could form along basic sections of freeway. For example, Koshi ${ }^{[4]}$ hypothesized that speed reduction occurred at sag sections. On the basis of this hypothesis, car-following behavior models of speed reduction and queue formation on sag sections were developed and calibrated, considering the influence of longitudinal gradient ${ }^{[5][6]}$. Although many types of car-following model have been proposed, the question of why traffic breakdown occurs at specific sags and tunnels remains unresolved ${ }^{[7]}$. Oguchi suggested several conditions of sags where could be bottlenecks, based on empirical observation data at 36 sags on Japanese freeways ${ }^{[8]}$. In terms of driving and car-following behavior, however, the detailed mechanisms of traffic breakdown are unclear, largely because of the difficulty of observing traffic flow and collecting traffic trajectory data under the same condition. That is, driving behavior can be influenced by many factors such as weather ${ }^{[9]}$, sunshine ${ }^{[10]}$, and surrounding traffic conditions, which cannot be managed by observers. In addition, driving and carfollowing behaviors vary widely among vehicles, depending on the roadway section ${ }^{[11][12]}$, and thus it is difficult to specify the true influence of sags on carfollowing behavior.

On the other hand, advances in information technology have allowed for experimental approaches using driving simulators (e.g., Hoogendoorn et al. ${ }^{[13]}$, Rong et al. ${ }^{[14]}$, Yang et al. ${ }^{[15]}$ ). If verified to be realistic, driving simulators can be useful for analyzing sag bottleneck phenomena. In a virtual reality environment, operators can manage all factors affecting car-following behavior, allowing the true influence of sags on carfollowing behaviors to be isolated and observed. Regarding sag bottlenecks, Oguchi and Iida showed that traffic congestion at sag bottlenecks could be represented in a car-following experiment using a driving simulator ${ }^{[16]}$. Their result supports the 
applicability of using driving simulators to analyze sag bottleneck phenomena.

In this study, we used the well-calibrated driving simulator developed by Oguchi and Iida ${ }^{[16]}$ to investigate the influence of freeway alignments on carfollowing behavior in an in-laboratory experiment. Concretely, we considered freeway alignments, including two types of sags and two types of curve sections, and two types of leading vehicle movement. Data on car-following and driving behavior were collected from 37 participants and analyzed with respect to each alignment and lead vehicle movement using statistical approaches. Finally, the mechanisms of speed reduction at specific types of sags are discussed.

Section 2 describes the design of the laboratory experiment using the driving simulator. In Section 3, the characteristics of driving behavior with respect to each road alignment and lead vehicle movement are analyzed focusing on the longitudinal change in the speed of following vehicles and accelerator opening degrees. Section 4 presents the estimated parameters of the carfollowing model, and the differences in the parameters with respect to road alignments and lead vehicle movements are verified by applying analysis of variance (ANOVA) and multiple comparisons. Finally, we discuss the speed reduction mechanism and measures to prevent traffic breakdown.

\section{Experimental design}

\subsection{Architecture of the driving simulator}

The driving simulator used in this study was developed by Oguchi and Iida ${ }^{[16]}$. Figure 1 shows the architecture of the simulator, which consists of a central processing unit, a visual generation system, a 3D sound system, and an automatic transmission driving operation unit that is a recreation of a real automatic transmission car with a speedometer. Although motion systems, such as vibration generators, were not built into the simulator, visual and acoustic features provide the driver with a sense of speed and acceleration.

Calibration and validation of a driving simulator are important for ensuring the accuracy and reliability of the simulated results. The simulator used in this study has been rigorously calibrated and validated since 1998 in terms of longitudinal change in driving speed and accelerator opening degree ${ }^{[17]}$. In particular, the reproducibility of the sag bottleneck phenomenon was verified $^{[16]}$. Thus, we considered this simulator to be sufficiently accurate and reliable for analyzing carfollowing behavior.

\subsection{Design of freeway alignments}

To investigate difference in car-following behavior with respect to freeway alignments, five types of driving courses were prepared: courses with (i) a gentle curve section, (ii) a sharp curve section, (iii) a gentle sag section, (iv) a sharp sag section, and (v) a normal straight section. Table 1 summarizes the freeway features of the experimental driving courses. In each driving course, certain points were indicated by kilometer posts $(\mathrm{kp})$ from the origin point. For example, in the gentle curve course, the experiment started at $2.5 \mathrm{kp}$ and ended at $4.5 \mathrm{kp}$; a participant drove the 2.0$\mathrm{km}$ distance, within which the driving data collected from 3.2 to $4.2 \mathrm{kp}$ were used for the analysis. Note that the sharp curve feature and the straight feature were included in the same course. Each course consisted of two lanes in one direction, and the lead and following vehicle were assumed to drive in the inner lane.

\subsection{Lead vehicle movements}

Lead vehicle movements can significantly affect the driving and car-following behavior of the following vehicle. For example, we can consider two possible reasons for deceleration of the following vehicle at a sag section: reaction to considerable deceleration of the lead vehicle and insufficient acceleration against the deceleration caused by the road alignment. It is necessary to separate these two influences on the following vehicle to clarify the influence of the freeway alignments.

Thus, we prepared two movement patterns for the lead vehicle: in one, a constant speed $(95 \mathrm{~km} / \mathrm{h})$ was



Figure 1. Architecture of the driving simulator

Table 1. Freeway alignments of each course

\begin{tabular}{|c|c|c|c|c|c|}
\hline \multirow{2}{*}{ Course } & \multirow{2}{*}{ Alignments of target section } & \multicolumn{2}{|c|}{ Driving course interval } & \multicolumn{2}{|c|}{ Target section interval } \\
\hline & & From & To & From & To \\
\hline Gentle curve & $\begin{array}{l}\text { Curvature radius: } 800 \mathrm{~m} \\
\text { Longitudial gradient: }+0.5 \% \\
\text { Curve section: from } 3.2 \mathrm{kp} \text { to } 4.1 \mathrm{kp}\end{array}$ & $2.5 \mathrm{kp}$ & $4.5 \mathrm{kp}$ & $3.2 \mathrm{kp}$ & $4.2 \mathrm{kp}$ \\
\hline Sharp curve & $\begin{array}{l}\text { Curvature radius: } 400 \mathrm{~m} \\
\text { Longitudial gradient: - } 0.5 \% \\
\text { Curve section: from } 8.9 \mathrm{kp} \text { to } 9.7 \mathrm{kp}\end{array}$ & $7.8 \mathrm{kp}$ & $12.0 \mathrm{kp}$ & $8.8 \mathrm{kp}$ & $9.8 \mathrm{kp}$ \\
\hline Gentle sag & $\begin{array}{l}\text { Curvature radius: } 1,000 \mathrm{~m} \\
\text { Longitudial gradient: }-1.9 \% \text { to }+1.6 \% \\
\text { Bottom of sag: from } 62.1 \mathrm{kp} \text { to } 62.0 \mathrm{kp}\end{array}$ & $63.2 \mathrm{kp}$ & $60.6 \mathrm{kp}$ & $62.5 \mathrm{kp}$ & $61.3 \mathrm{kp}$ \\
\hline Sharp curve & $\begin{array}{l}\text { Curvature radius: } 1,000 \mathrm{~m} \\
\text { Longitudial gradient: }-1.9 \% \text { to }+5.0 \% \\
\text { Bottom of sag: from } 62.1 \mathrm{kp} \text { to } 62.0 \mathrm{kp}\end{array}$ & $63.2 \mathrm{kp}$ & $60.6 \mathrm{kp}$ & $62.5 \mathrm{kp}$ & $61.3 \mathrm{kp}$ \\
\hline Straight & $\begin{array}{l}\text { Curvature radius: } 4,000 \mathrm{~m} \\
\text { Longitudial gradient: }-2.5 \%\end{array}$ & $7.8 \mathrm{kp}$ & $12.0 \mathrm{kp}$ & $8.2 \mathrm{kp}$ & $8.8 \mathrm{kp}$ \\
\hline
\end{tabular}


maintained despite the road alignments ("constant case"), and in the other driving speed varied "naturally" in accordance with the freeway alignments ("natural case"). For the natural case, we generated a driving profile of the lead vehicle by operating the driving simulator on the basis of a speed-profile model of the relationship between free-flow speed and roadway alignments ${ }^{[18]}$. In the speed-profile model, the basic speed was set as 100 $\mathrm{km} / \mathrm{h}$. On sag and curved sections, the lead vehicle speed became around $95 \mathrm{~km} / \mathrm{h}$, which is the same as the speed in the constant case.

\subsection{Design of traffic conditions}

To produce as realistic a driving situation as possible, surrounding vehicles were allocated around the lead and following vehicles. Several vehicles were located in front of the lead vehicle and behind the following vehicle, from $250 \mathrm{~m}$ apart, so as not to influence on the following vehicle's driving behavior. Additionally, in the shoulder lane, other vehicles were allocated alongside for the whole course; the vehicles maintained distances of $70 \mathrm{~m}$ from each other and moved at $90 \mathrm{~km} / \mathrm{h}$, to simulate a relatively congested traffic situation. In the inner lane, all vehicles including the lead and following vehicles were passenger cars, whereas in the outer lane $30 \%$ of the vehicles were trucks.

\subsection{Participants and procedures}

All participants were randomly selected from university students with a valid driver license. Thirtyseven drivers ( 27 males, 10 females) participated in the experiment. The participants ranged from 21 to 26 years of age, with a mean of 23.4 years $(S D=1.32)$. Driving experience varied from 1 month to 6 years, with a mean of 2.99 years $(\mathrm{SD}=1.66)$.

Each driver was instructed to follow the lead vehicle in eight experimental cases, consisting of two cases for the movement of the lead vehicle in each of the four driving courses. The order of the eight cases was randomized to eliminate any order effect. That is, all the participants completed the cases in a different order. Before the experiment, each participant had $20 \mathrm{~min}$ to drive and become accustomed to the simulator. All participants received monetary compensation for their participation in the experiment.

\section{Fundamental analysis of driving behavior}

This section overviews the differences in driving and car-following behavior by case based on longitudinal changes in driving speed and accelerator opening degrees of the following vehicle.

\subsection{Longitudinal change in driving speed}

Figures 2, 3, 4, and 5 show the longitudinal change in average driving speed of all participants for the gentle sag section, sharp sag section, gentle curve section, and sharp curve section, respectively. In the figures, the longitudinal changes in lead vehicle speed, and the changes in altitude for inclined sections and curvature radii for curved sections, are also illustrated.

For both sag sections, the points where the average speed is lowest tend to be located more downstream in the natural case, where a lead vehicle varies its driving speed according to the road alignments, than in the constant case, where the lead vehicle maintains a constant speed despite road alignment. That is, in the constant case, the following vehicles accelerate earlier than in the natural case. This indicates that when the lead vehicle maintains its speed throughout the whole section, the driver of the following vehicle notices the speed gap at an earlier stage and thus can recover speed before a large speed reduction occurs.

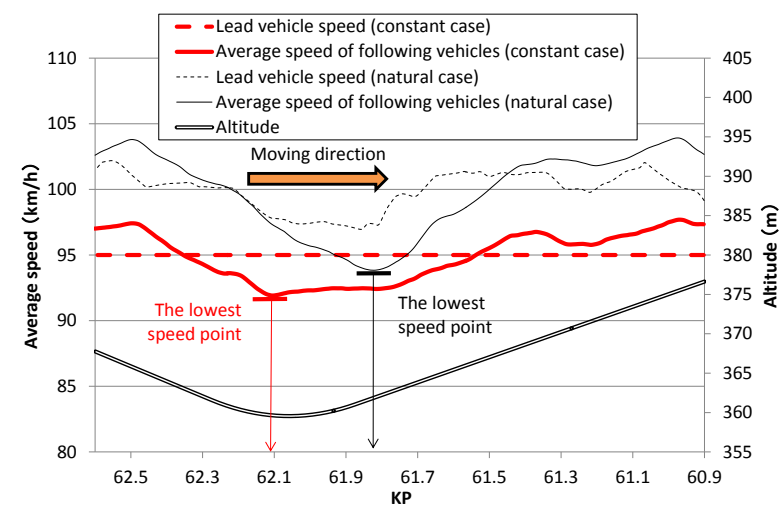

Figure 2. Longitudinal speed changes on the gentle sag section.

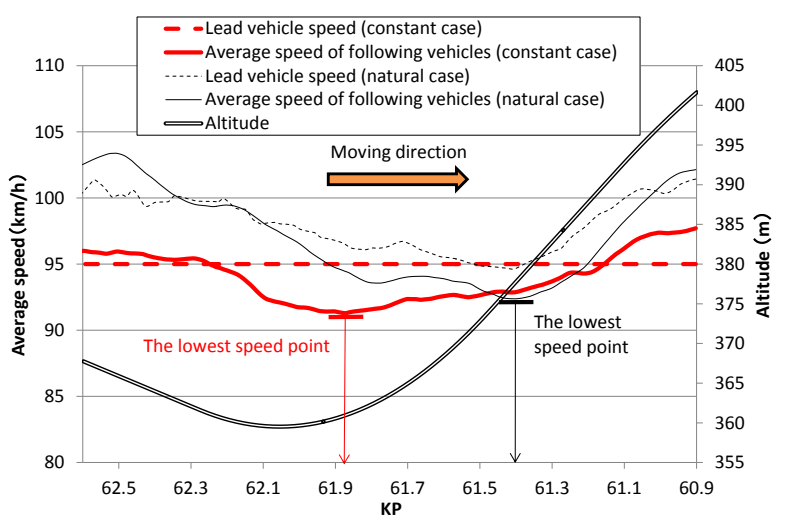

Figure 3. Longitudinal speed changes on the sharp sag section. 


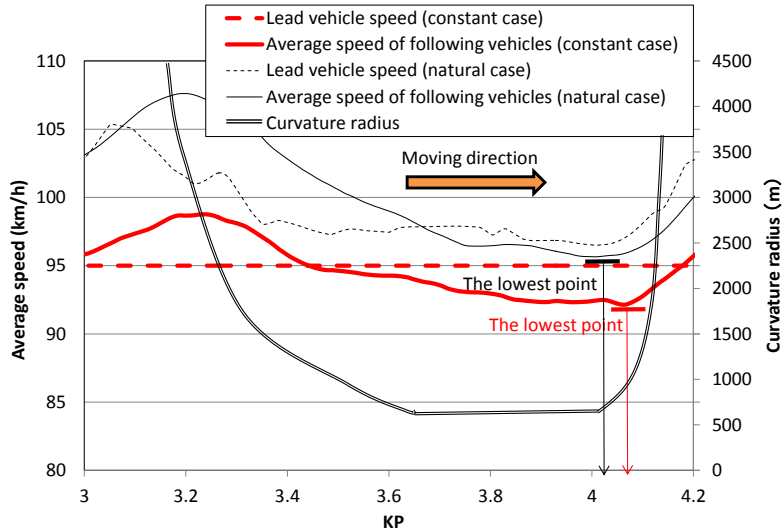

Figure 4. Longitudinal speed changes on the gentle curve section.

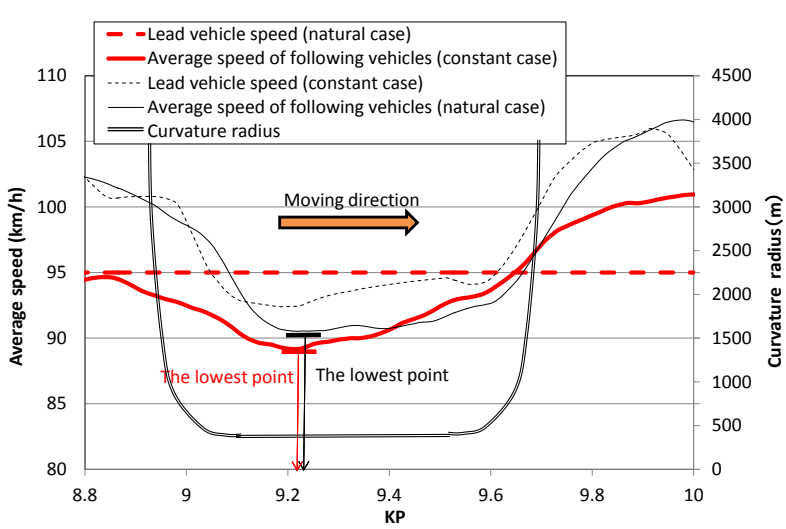

Figure 5. Longitudinal speed changes on the sharp curve section.

In contrast, the tendency is different in the curve sections. From Figures 4 and 5, it can be seen that the points where the following vehicles take the lowest speed are almost same regardless of the lead vehicle movement. It must be because in the curve section the influence of the road alignment on the driving behavior is more significant than of the lead vehicle movement. The driver should operate the handle as well as the accelerator to follow the lane safely. This tendency is confirmed by the fact that on the gently curved section, the driving speed gradually decreased as the curvature radius decreased, whereas on the sharp curve section, driving speed decreased suddenly with the sudden reduction in the curvature radius.

\subsection{Longitudinal change in accelerator opening degrees}

To further analyze the driving behavior of the following vehicle, the accelerator opening degree was analyzed. This measure was defined in the interval from $0 \%$ to $100 \%$ in the angle of the accelerator pedal position. Figures 6, 7, and 8 summarize the longitudinal changes in the average of the accelerator opening degree

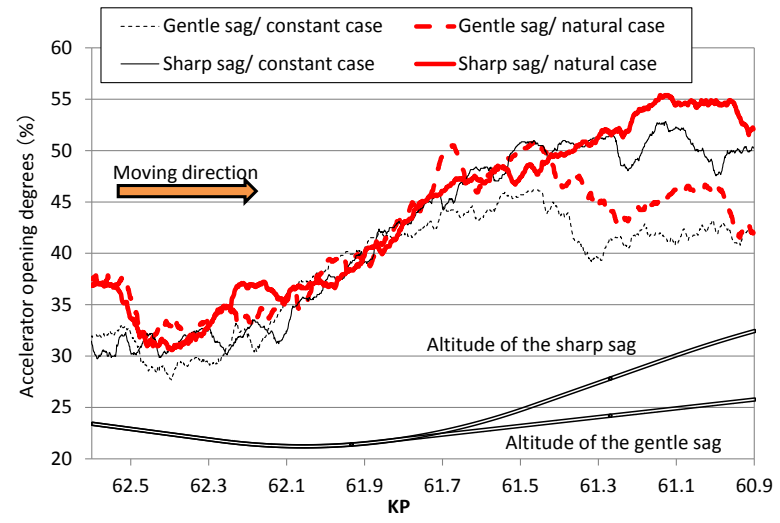

Figure 6. Longitudinal change in accelerator opening degree on sag sections.

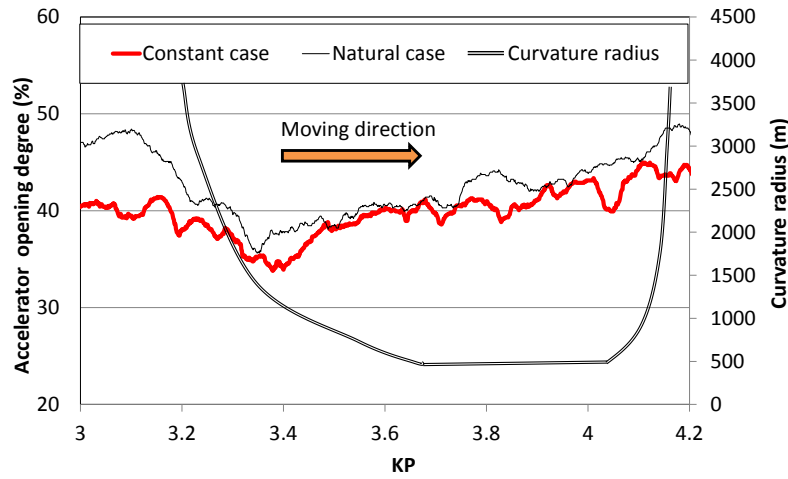

Figure 7. Longitudinal change in accelerator opening degree on the gentle curve section.

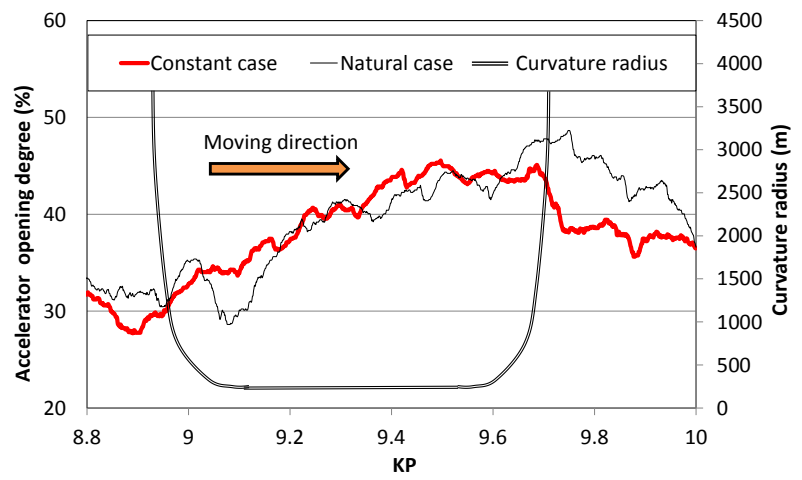

Figure 8. Longitudinal change in accelerator opening degree on sharp curve section.

on the sag sections, on the gently curved section, and on the sharply curved section, respectively.

Figure 6 shows that after taking the lowest value around $62.4 \mathrm{kp}$, the accelerator opening degree increased, from $62.2 \mathrm{kp}$ to $61.5 \mathrm{kp}$, at almost the same rate regardless of road alignments or lead vehicle movement. On the gentle sag section, the opening degree increased to $45 \%$, while on the sharp sag section it increased to $50 \%$ or $55 \%$. These results indicate that the accelerator opening degree needed to increase the driving speed differs depending on the gradient of the incline. When 
the upgrade is steeper, it takes more time to open the accelerator to a sufficient degree to increase the speed. Thus, on the sharp sag section, the points where the driving speed was lowest were located farther downstream than in the gentle sag section.

On the curved section, the opening degree decreased in the section where the curvature radius decreased, as shown in Figures 7 and 8, and after the radius became stable, the degree of opening tended to increase. This tendency was observed in both the constant and natural cases. This result is consistent with the longitudinal speed changes shown in Figures 4 and 5. Thus, speed reduction on the curved section was apparently caused primarily by the driver's behavior in response to the change in the radius of curvature.

\section{Analysis of parameters of car-following models}

Analysis of the accelerator opening degree reveals the influence of road alignments on car-following and driving behaviors. To investigate the influence of road alignments in terms of car-following behavior, the parameters of car-following models were estimated and the relationship between parameters and road alignments was investigated.

\subsection{Estimation of car-following model parameters}

Parameters were estimated with respect to each pair of trajectories of the lead vehicle and following vehicle. The experiments involved two cases of lead vehicle movements with respect to five target sections for 37 participants; thus, in total 370 ( 2 cases $\times 5$ sections $\times$ 37 participants) sets of parameters could be estimated. Data about acceleration, speed, and coordinates of each vehicle required for the parameter estimation were collected every $0.1 \mathrm{~s}$. The estimated parameters were analyzed by applying ANOVA in which the movements of the lead vehicle and road alignments were considered as explanatory variables.

4.1.1. Choice of car-following model. Among numerous car-following models, the Helley model ${ }^{[19]}$ expressed in Eq. (1) was chosen. This model assumes a linear relationship between the acceleration and the relative speed and headway distance, and allows for straightforward interpretation of the estimated parameters. Note that this study aims for understanding the influence of road alignments on car-following behavior, instead of establishing a car-following model considering the influence of road alignments.

$\ddot{x}_{1}(t+\Delta t)=a_{1}\left(\dot{x}_{0}(t)-\dot{x}_{1}(t)\right)+a_{2}\left(x_{0}(t)-x_{1}(t)\right)+a_{3}$,

where

$\ddot{x}_{i}(t):$ the acceleration of vehicle $i$ at time $t$, $\dot{x}_{i}(t)$ : the speed of vehicle $i$ at time $t$,

$x_{i}(t)$ : the coordinate of vehicle $i$ exists at time $t$

$i$ : 0 indicates a lead vehicle and 1 indicates a following vehicle,

$\Delta t$ : reaction time and

$a_{1}, a_{2}, a_{3}$ : estimation parameters.

In Eq. (1), the constant value $a_{3}$ can be included in the second term of the right side as follows:

$$
\begin{aligned}
\ddot{x}_{1}(t+\Delta t) & =a_{1}\left(\dot{x}_{0}(t)-\dot{x}_{1}(t)\right)+a_{2}\left(x_{0}(t)-x_{1}(t)+\frac{a_{3}}{a_{2}}\right) \\
& =a_{1}\left(\dot{x}_{0}(t)-\dot{x}_{1}(t)\right)+a_{2}\left(x_{0}(t)-x_{1}(t)-\Delta d\right)
\end{aligned}
$$

where $\Delta d\left(=-a_{3} / a_{2}\right)$ indicates the desired gap between the lead vehicle and following vehicle.

Parameters were estimated by applying the leastsquares method with $\Delta t$ changing from $0.1 \mathrm{~s}$ to $3.0 \mathrm{~s}$ by $0.1 \mathrm{~s}$. Among the various $\Delta t$, the value at which the adjusted $R^{2}$ is maximized was determined as the estimated reaction time. Note that the reaction time was estimated for each trial, and thus, the estimated reaction time may vary even within the same participant's data.

4.1.2. Conditions of the following behavior. Although participants were instructed to follow the lead vehicle, there were some participants who did not catch up with the lead vehicle and, as a result, could not follow it. In such cases, the estimated parameters of the Helley model do not have significant meanings. The following four criteria were considered, and data that did not satisfy the criteria were eliminated.

Criterion 1: The following vehicle maintains less than $3.0 \mathrm{~s}$ headway to the lead vehicle for $5.0 \mathrm{~s}$ or more.

Criterion 2: The time-series change in the relative speed between the lead vehicle and the following vehicle is neither monotone decreasing nor monotone increasing.

Criterion 3: The coefficient of determinant of the parameter estimation is 0.3 or more.

Criterion 4: The correlation coefficient between the relative speed and the headway distance, which are both explanatory variables in the Helley model in Eq. (1), is less than 0.9 .

Criterion 1 was intended to eliminate drivers who did not follow the lead vehicle because of insufficient acceleration. In Criterion 2, monotone increase in relative speed represents a situation in which the following vehicle is being left behind by the lead vehicle. Monotone decrease corresponds to the situation in which the following vehicle is just catching up with the lead vehicle. These situations were irrelevant to the focus of the present analysis. Criterion 3 removes drivers whose following behaviors do not fit the Helley model, and Criterion 4 indicates the general condition to check for multicollinearity in the regression analysis. After 
eliminating data, 253 samples remained for further analyses. The number of samples in each case is summarized in Table 2.

\subsection{Comparisons of estimated parameters}

Using the data set prepared in the previous section, differences in the estimation parameters of the carfollowing model among the experimental cases are discussed using ANOVA.

4.2.1. Relative speed and headway distance. Tables 3 and 4 summarize the results of two-way ANOVA relating to $\hat{a}_{1}$ and $\hat{a}_{2}$, in which the lead vehicle movements were considered as one factor with two levels (constant case and natural case) and the road alignments were considered as the other factor, with five levels (gentle sag, the sharp sag, the gentle curve, sharp curve and straight).

Table 3 shows that the estimation parameters of relative speed were significantly different by road alignments at the $1 \%$ significant level, whereas the factor of the lead vehicle movement and the interaction term were not. Similarly, with respect to the estimation parameters of the headway distance, Table 4 shows the same tendency with the estimations of relative speed, although the interaction term was significant at the 5\% level. These results suggest that (i) road alignments significantly influence car-following behavior, and (ii) although the longitudinal changes in driving speed of the following vehicle differ, depending on lead vehicle movement, the accelerating and decelerating mechanisms represented by the car-following model proposed by Helley were the same despite lead vehicle movements. Thus, we now focus on the influence of road alignments on following behavior.

Figures 9 and 10 show the average estimated parameters with respect to each road alignment. In both figures, parameter values were highest in the straight road section and gradually decreased in the order of curved sections and sag sections. The reasons may be as follows. In the straight road section, there is no obstruction for drivers in the sense of acceleration/deceleration, and thus the driver can accelerate/decelerate as he/she likes. On the other hand, at sag sections, due to the effect of gravity, a driver is obstructed with regard to decelerating in downgrade sections and accelerating in the upgrade sections. That is, a vehicle can get less output in sag sections than in the straight section even if the amount of input is the same, and consequently the estimated parameters in inclined sections may be less than those in the straight section. It is also reasonable that the estimated parameters on the curved sections were less than those on the straight section and larger than the sag sections. In curved sections, there is no factor to directly affect acceleration or deceleration, but the acceleration behavior may be
Table 2. Number of samples in each case

\begin{tabular}{c|rrrrrr|}
\hline & \multicolumn{1}{|c}{$\begin{array}{c}\text { Gentle } \\
\text { sag }\end{array}$} & $\begin{array}{c}\text { Sharp } \\
\text { sag }\end{array}$ & $\begin{array}{c}\text { Gentle } \\
\text { curve }\end{array}$ & $\begin{array}{c}\text { Sharp } \\
\text { curve }\end{array}$ & Straight & Total \\
\hline $\begin{array}{c}\text { Constant } \\
\text { case }\end{array}$ & 30 & 19 & 27 & 18 & 29 & 123 \\
\hline $\begin{array}{c}\text { Variable } \\
\text { case }\end{array}$ & 29 & 25 & 30 & 27 & 33 & 144 \\
\hline Total & 59 & 44 & 44 & 44 & 62 & 253 \\
\hline
\end{tabular}

Table 3. ANOVA of the estimated parameters related to relative speed

\begin{tabular}{l|r|r|r|r|r}
\hline & $\begin{array}{r}\text { Sum of } \\
\text { square }\end{array}$ & df & $\begin{array}{c}\text { Mean } \\
\text { square }\end{array}$ & $\mathrm{F}$ & $\mathrm{p}$-value \\
\hline (a) The lead vehicle movements & 0.004 & 1 & 0.004 & 0.15 & 0.694 \\
(b) Road al ignments & 0.53 & 4 & 0.133 & 5.15 & 0.001 \\
Interaction of (a) * (b) & 0.181 & 4 & 0.045 & 1.75 & 0.139 \\
Error & 6.63 & 257 & 0.026 & & \\
Total & 22.58 & 267 & & & \\
Corrected total & 7.37 & 266 & & & \\
\hline
\end{tabular}

Table 4. ANOVA of the estimation parameters related to headway distance

\begin{tabular}{l|r|r|r|r|r}
\hline & $\begin{array}{r}\text { Sum of } \\
\text { square }\end{array}$ & df & \multicolumn{1}{c|}{$\begin{array}{c}\text { Mean } \\
\text { square }\end{array}$} & \multicolumn{1}{c|}{$\mathrm{F}$} & $\mathrm{p}$-value \\
\hline (a) The lead vehicle movements & 0.003 & 1 & 0.003 & 2.013 & 0.157 \\
(b) Road al ignments & 0.029 & 4 & 0.007 & 5.39 & 0.000 \\
Interaction of (a)* (b) & 0.014 & 4 & 0.003 & 2.56 & 0.039 \\
Error & 0.344 & 257 & 0.001 & & \\
Total & 0.631 & 267 & & & \\
Corrected total & 0.388 & 266 & & & \\
\hline
\end{tabular}

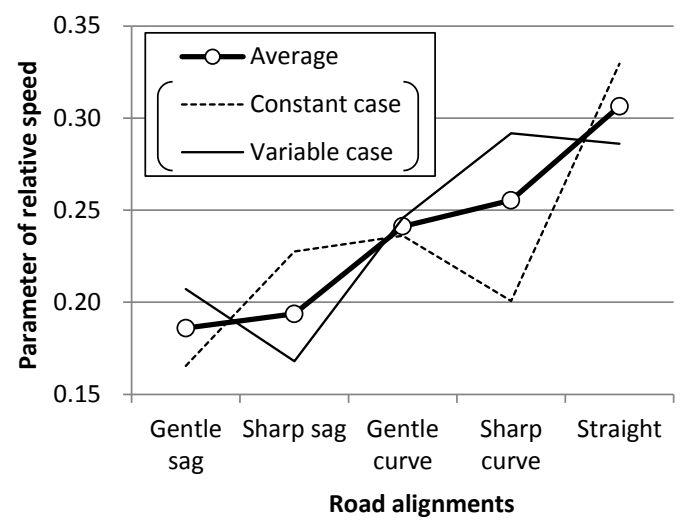

Figure 9. Estimated relative speed

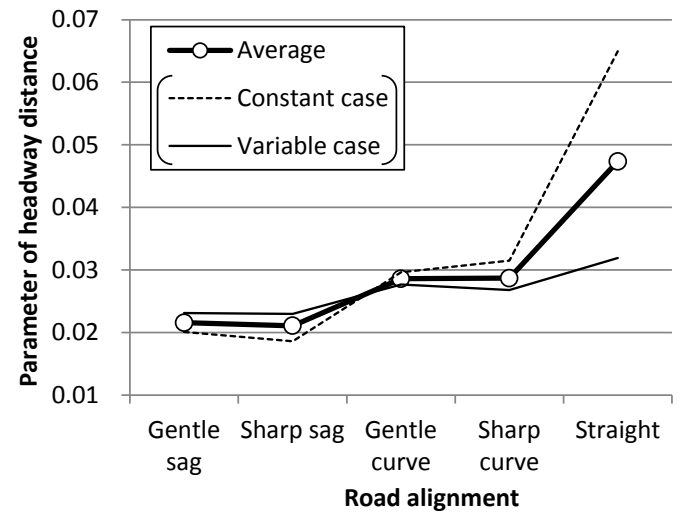

Figure 10. Estimated headway distance 
significantly influenced by adjusting the steering wheel and accelerator pedal to follow the lane safely.

4.2.2. Reaction time. Table 5 summarizes the results of two-way ANOVA related to the estimation of reaction time $\Delta \bar{t}$, and Figure 11 provides the estimation values in each case. In the ANOVA, only the factor relating to road alignments showed a difference at the $1 \%$ significance level, as with the other parameters. This result indicates that regardless of the characteristics of the lead vehicle movement, the driver in the following vehicle adjusts the acceleration to the movement of the lead vehicle in the same manner.

When focusing on the estimated values, we can see that the sharp sag and the gentle curve provided the higher values, followed by the gentle sag, the sharp curve, and the straight section. The longer reaction time in the sag sections versus the straight section can be explained by the gravity effect. Because of gravity, a vehicle naturally accelerates on the downgrade section and decelerates on the upgrade section. As shown in Figure 6, the accelerator opening degree required to increase the speed depends on the gradient and it took more time to reach the required opening degree in the sharp gradient section than in the gentle section. Thus, the estimated reaction time in the sag section is higher than in the straight section, and it also makes sense that the reaction time is higher in the sharp sag section than in the gentle sag section.

In the gentle curve section, because the radius of curvature changes gradually over a longer distance than for the sharp curve section, the driver must pay attention to following the curve for a long time. As a result, the perception of the difference in the relative speed and the headway time is delayed. For a more detailed analysis, further investigation relating to eye movement or mental workload is required.

4.2.3. Desired gap. As mentioned in 4.1.1, the desired distance between the lead vehicle and the following vehicle can be estimated by $-\hat{a}_{3} / \hat{a}_{2}$. The driver of the following vehicle is assumed to react to the distance of the headway distance minus the desired gap. ANOVA was used to investigate differences in the estimated desired gaps. The results are summarized in Table 6 and the estimation is shown in Figure 12.

The results indicate that there was no significant difference in the desired gap among the lead vehicle movements and the road features at the $5 \%$ significance level. This tendency was also confirmed by Figure 12 . The desired gap indicates perceptual aspects of drivers and thus depends on the drivers and the experimental environment. The estimated desired gap would be the same if the driver and driving environments, such as the driving speed, type of vehicles, and surrounding conditions, were the same. Thus, the results shown in
Table 5. ANOVA of the estimated reaction times

\begin{tabular}{|c|c|c|c|c|c|}
\hline & $\begin{array}{l}\text { Sum of } \\
\text { square }\end{array}$ & df & $\begin{array}{l}\text { Mean } \\
\text { square }\end{array}$ & $\mathrm{F}$ & $\mathrm{p}$-value \\
\hline (a) The lead vehicle movements & 0.978 & 1 & 0.978 & 1.446 & 0.230 \\
\hline (b) Road al ignments & 15.63 & 4 & 3.908 & 5.77 & 0.000 \\
\hline Interaction of (a) $*$ (b) & 0.874 & 4 & 0.219 & 0.323 & 0.863 \\
\hline Error & 173.9 & 257 & 0.677 & & \\
\hline Total & 1244.6 & 267 & & & \\
\hline Corrected total & 191.7 & 266 & & & \\
\hline
\end{tabular}

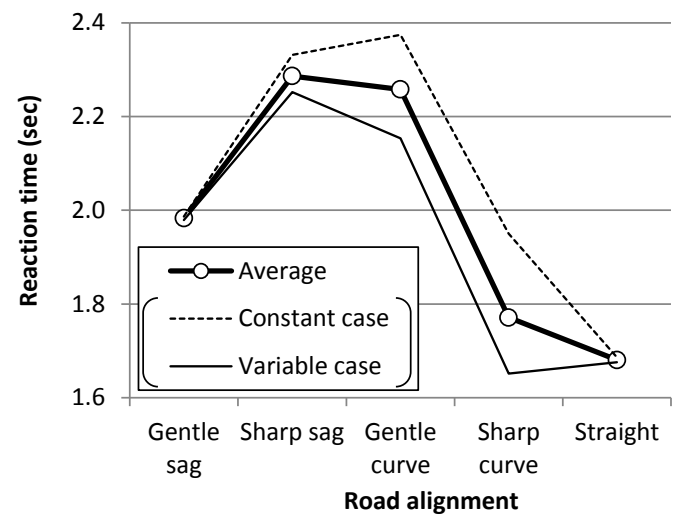

Figure 11. Estimation of reaction time

Table 6. ANOVA of the estimated desired gap

\begin{tabular}{l|r|r|r|r|r}
\hline & $\begin{array}{c}\text { Sum of } \\
\text { square }\end{array}$ & df & $\begin{array}{c}\text { Mean } \\
\text { square }\end{array}$ & $\mathrm{F}$ & $\mathrm{p}$-value \\
\hline (a) The lead vehicle movements & 116.6 & 1 & 116.6 & 0.074 & 0.786 \\
(b) Road al ignments & 8866.0 & 4 & 2216.5 & 1.398 & 0.235 \\
Interaction of (a) * (b) & 7898.3 & 4 & 1974.6 & 1.246 & 0.292 \\
Error & 407404.2 & 257 & 1585.2 & & \\
Total & 933871.0 & 267 & & & \\
Corrected total & 424119.2 & 266 & & & \\
\hline
\end{tabular}

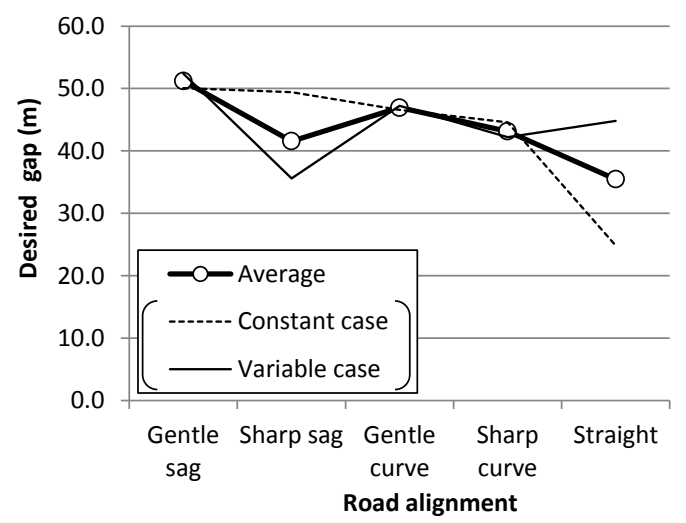

Figure 12. Estimation of desired gap

Table 6 and Figure 12 seem reasonable and support the validity of the experiment.

\subsection{Discussion}

This study found that reaction times were longer and the estimated parameters of relative distance and relative speed were longer and lower, respectively, on the gentle and sharp sag and gently curved sections than on the normal straight section. Generally, higher parameter 
values and reaction times indicate a lower stability of car-following ${ }^{[20]}$. However, as long as local stability and asymptotic stability are satisfied, when the lead vehicle decelerates at the bottom of a sag section, the following vehicle with smaller parameters and longer reaction time would be likely to shorten the relative distance because the following vehicle would take more time to decelerate to the same speed as the lead vehicle. In turn, when the lead vehicle accelerates after passing through the bottom of a sag section, a following vehicle with smaller parameters and longer reaction time would take longer to catch up with the lead vehicle. It would be why platoons with high density are likely to be generated at the bottom of sag sections, which have been found to induce speed reduction and traffic breakdown ${ }^{[4][21]}$. Thus, in such a section, a measure to prevent platoon formation would be effective in preventing traffic breakdown and mitigating traffic congestion. Based on the discussion, reducing the reaction time and/or increasing the value of car-following parameters would help mitigate bunching. In this sense, adaptive cruise control to assist the following vehicle's acceleration and deceleration could be a possible measure to help prevent traffic breakdown.

\section{Conclusions}

In the present study, we investigated the relationship between car-following behavior and freeway alignments by a laboratory experiment using a well-calibrated driving simulator. In the experiment, five types of road alignment were considered: gentle curve, sharp curve, gentle sag, sharp sag, and straight section. The movement of the lead vehicle was (i) kept at a constant speed along with the whole course and (ii) varied naturally according to the freeway alignments. In total, 37 participants took part in the experiment.

First, focusing on the longitudinal change in the average speed and the average accelerator opening degree for all participants, the influence of road features on following behavior was examined. The data revealed that in sag sections, the required accelerator opening degree for acceleration varied depending on the upgrade gradient and the target speed, which caused a delay in recovering driving speed. At the beginning of a curve, the following vehicle reduced the accelerator angle and then tried to recover its speed again. In the recovering period, the gradual changes in the radius of curvature may have caused a delay in recovering the speed.

Then, the parameters of the car-following model were estimated and analyzed in relation to freeway alignments. This showed that (i) the parameters of the following model varied significantly with respect to freeway alignments, and (ii) differences in the movement of the lead vehicle did not affect the estimated parameters. Furthermore, in the sag section, the parameters of the relative speed and headway distance tended to be lower and the reaction time tended to be higher. This suggests that when vehicles passed through s sag section, headway distance between the successive vehicles was likely to shorten and the accumulation of the vehicles with the short headway distances possibly caused traffic breakdown.

Some of the issues discussed here require further analysis. For example, the quantitative relationship between the freeway gradient and the required accelerator opening degree for acceleration remains unclear. The heterogeneity of driving behavior should also be considered in future research. Moreover, perception-reaction mechanisms and psychological aspects are important in understanding bottleneck phenomena on sag sections and in developing advanced measures to prevent traffic breakdown, such as adaptive cruise control and driver assist systems.

\section{References}

[1] Koshi, M., Kuwahara, M., Akahane, H., 1992. Capacity of sags and tunnels in Japanese motorways. ITE Journal, 17-22.

[2] Hikosaka, T., Nakamura, H., 2001. Statistical analysis on the relationship between traffic accident rate and traffic flow condition in basic expressway sections. Proceedings of the 21st Japan Society of Traffic Engineers (JSTE) Meeting, 173-176. (in Japanese).

[3] Koshi, M., Iwasaki, M., Ohkura, I., 1983. Some findings and an overview on vehicular flow characteristics. In: Hurdle, V. F., Hauer, E., Steuart, G. N. (Eds.), Proceedings of the Eighth International Symposium on Transportation and Traffic Theory, University of Toronto Press, Toronto, 403-451.

[4] Koshi, M., 1986. Capacity of motorway bottlenecks. Journal of the Japan Society of Civil Engineers 371(IV5), 1-7 (in Japanese).

[5] Ozaki, H., 1993. Reaction and anticipation in the carfollowing behavior. Proceedings of $12^{\text {th }}$ ISTTT (Berkley), 349-366.

[6] Xing, J., Koshi, M., 1995. A study on the bottleneck phenomena and car-following behavior on sags of motorways. Journal of Infrastructure Planning and Management 506 (IV-26), 45-55 (in Japanese).

[7] Oguchi, T., 2000. Analysis of bottleneck phenomenon at a basic freeway segments - car following model and future exploration -. Journal of Infrastructure Planning and Management 660 (IV-49), 39-51. (in Japanese).

[8] Oguchi, T., 1995. Relationship between traffic congestion phenomena and road alignments at sag sections on motorways. Journal of Infrastructure Planning and Management 524 (IV-29), 69-78. (in Japanese).

[9] Chung, E., Ohtani, O., Warita, H., Kuwahara, M., Morita, H., 2006. Does weather affect highway capacity? Proceedings of the 5th TRB International 
Symposium on Highway Capacity and Quality of Service,

[10] Kusakabe, T., Iryo, T., Asakura, Y., 2010. Data mining for traffic flow analysis: Visualization approach. In: Barceló, M. Kuwahara (eds.), Traffic data collection and its standardization. Springer Series, 57-72.

[11] Hong, D., Uno, N., Kurauchi, F., Imada, M., 2007. Empirical analysis of drivers' car-following heterogeneity based on video image data. Proceedings of the 12th International Conference of Hong Kong Society for Transportation Studies, 401-410.

[12] Ossen, S, Hoogendoorn, S.P., 2011. Heterogeneity in car-following behavior: Theory and empirics. Transportation Research Part C 19 (2), 182-195.

[13] Hoogendoorn, R.G., Hoogendoorn, S.P., Brookhuis, K.A., Daamen, A., 2011. Adaptation effects in longitudinal driving behavior: mental workload and psycho-spacing models in case of fog. Transportation Research Board 90 ${ }^{\text {th }}$ Annual Meeting DVD-ROM.

[14] Rong, J., Mao, K., Ma., J. 2011. Effects of individual differences on driving behavior and traffic flow characteristics. Transportation Research Board $90^{\text {th }}$ Annual Meeting DVD-ROM.

[15] Yang, Q., Overton, R. Han, L.D., Yan, X., Richards, S. H., 2011. Driver behaviors on rural highways with and without curbs - a driving simulator based study. Transportation Research Board $90^{\text {th }}$ Annual Meeting DVD-ROM.

[16] Oguchi, T., Iida, K. 2003. Applicability of driving simulator technique for analysis of car-following behavior at sag sections on expressways. Journal of Japan Society of Traffic Engineers 38 (4) 41-50 (in Japanese).

[17] Iida, K., Mori, Y., Kim, J., Ikeda, T., Miki, T., 1998. Development of the laboratory test system using virtual reality simulation: reproducibility at the entrance of tunnel on expressway. Proceedings of Infrastructure Planning Conference 21(1), 507-510 (in Japanese).

[18] Ottesen, J.L., Krammes, R.A., 2000. Speed-profile model for a design-consistency evaluation procedure in the United States. Transportation Research Record 1701, 76-85.

[19] Helley, W., 1959. Simulation of bottlenecks in single-lane traffic flow. Theory of Traffic Flow, pp.207238.

[20] Gazis, D.C., Herman, R., Potts, R.B., 1959. Carfollowing theory of steady-state traffic flow. Operations Research 7, 499-505.

[21] Shiomi, Y., Yoshii, T., Kitamura, R., 2011. Platoon-based traffic flow model for estimating breakdown probability at single-lane expressway bottlenecks. Transportation Research Part B 45(9), pp.1314-1330. 